\title{
Investigation on Nickel-Titanium Rotary Instruments in Endodontics
}

\author{
Alessandro Mazzoni ${ }^{1}$, Alessio Zanza ${ }^{2}$, Rodolfo Reda ${ }^{3}$, Shilpa Bhandi ${ }^{4}$, Andrea Del Giudice ${ }^{5}$, Gabriele Miccoli ${ }^{6}$ \\ World Journal of Dentistry (2021): 10.5005/jp-journals-10015-1792
}

Before the introduction of the nickel-titanium (Ni-Ti) alloy for the production of rotary instruments, ${ }^{1}$ root canal treatments (RCTs), were used to be performed only by using manual stainless steel (SS) files with longer times of intervention, multiple appointments, and other difficulties often experienced also by expert clinicians. ${ }^{2}$ Canal transportations and root perforations, especially in curved canals, were the most drawbacks encountered during RCTs performed with non-superelastic instruments. Moreover, it was necessary to follow longer and complex instrumentation protocols that were more difficult to perform. ${ }^{3}$

$\mathrm{Ni}$-Ti rotary (NTR) instruments allowed clinicians to approach root canal instrumentation in a reproducible and standardized way, with less risk of iatrogenic errors during intracanal instrumentation. ${ }^{4}$

Many generations of $\mathrm{Ni}$-Ti files have been produced in the last decades, passing from simpler designs, to increasingly complex cross-sections to improve cutting efficacy and resistance to fracture even in most challenging narrow, curved root canals., 6

The use of Ni-Ti instruments simplified the shaping procedures of the root canal, making the removal of pulp tissue and infected dentin more efficient than the SS manual files. Furthermore, the increased efficacy in shaping founds its major impact in cleaning and filling procedures. ${ }^{7}$ The particular design of many instruments, with a variable taper and peculiar cross-sections, could permit the irrigants to flow through the apical portion of the root canal, with the possibility of sonic or ultrasonic activation performed by many different devices: this could lead to proper disinfection of the root canal system, ensuring the goal of the treatment. ${ }^{8}$ However, the prolonged use of these instruments may present some drawbacks: the influence of flexural and torsional stresses to the alloy may alter the characteristics of the crystalline structure of the alloy and leads the instrument to intracanal separation. ${ }^{9,10}$ Hence, in literature, many authors investigated the main reasons for failure during instrumentation: torsional failure could happen when the instrument continues to rotate while the tip is taper locked. ${ }^{6,11}$ Cyclic fatigue failure is the result of continuative compressive and tensile stresses that concentrates themselves at the maximum curvature point of the instrument. ${ }^{12}$ It is clear that these two stresses are the most representative cause of NTR fracture, and both could occur alone or combined.

In the last years, manufacturers have focused their attention to develop $\mathrm{Ni}-\mathrm{Ti}$ instruments with improved resistance to both types of fracture: thermal treatments demonstrated that they can enhance both cyclic and torsional resistance by improving the quality of the microcrystalline pattern of the alloy. ${ }^{13}$ Recently developed instruments have been designed to be used as a single file system and thermal treatments are considered a helpful way to maintain the file's flexibility, centering ability, and resistance to
1-3,5,6 Department of Oral and Maxillo-Facial Sciences, Sapienza University of Rome, Rome, Italy

${ }^{4}$ Department of Restorative Dental Sciences, Jazan University, Jazan, Kingdom of Saudi Arabia

Corresponding Author: Andrea Del Giudice, Department of Oral and Maxillo-Facial Sciences, Sapienza University of Rome, Rome, Italy, Phone: +393315951850, e-mail: andrea.delgiudice@uniroma1.it

How to cite this article: Mazzoni A, Zanza A, Reda R, et al. Investigation on Nickel-Titanium Rotary Instruments in Endodontics. World J Dent 2021;12(1):1-2.

Source of support: Nil

Conflict of interest: None

flexural and torsional fracture. ${ }^{14}$ In conclusion, it is clear that the aim of the development of new generation NTR instruments should permit a minimal invasive endodontic treatment and reduce the major drawbacks during intracanal instrumentation, such as, root perforation, zips, and ledge. New generation instrument should ensure the most efficient irrigation technique and keep long-lasting characteristic and fracture resistance due to avoid the most possible, intraoperational complications.

\section{References}

1. Walia HM, Brantley WA, Gerstein H. An initial investigation of the bending and torsional properties of nitinol root canal files. J Endod 1988;14(7):346-351. DOI: 10.1016/S0099-2399(88) 80196-1.

2. Rowan MB, Nicholls Jl, Steiner J. Torsional properties of stainless steel and nickel-titanium endodontic files. J Endod 1996;22(7):341-345. DOI: 10.1016/S0099-2399(96)80214-7.

3. Sonntag D, Guntermann A, Kim SK, et al. Root canal shaping with manual stainless steel files and rotary $\mathrm{Ni}$-Ti files performed by students. Int Endod J 2003;36(4):246-255. DOI: 10.1046/j.13652591.2003.00661.x.

4. Reda R, Zanza A, Reda R, et al. A comprehensive in vitro comparison of mechanical properties of two rotary endodontic instruments. World J Dentis 2020;11(3):185-188. DOI: 10.5005/jp-journals-10015-1729.

5. Di Nardo D, Gambarini G, Seracchiani M, et al. Influence of different cross-section on cyclic fatigue resistance of two nickel-titanium rotary instruments with same heat treatment: an in vitro study. Saudi Endod J 2020;10(3):221-225.

6. Di Nardo D, Seracchiani M, Mazzoni A, et al. Torque range, a new parameter to evaluate new and used instrument safety. Appl Sci 2020;10(10):3418. DOI: 10.3390/app10103418.

7. Mazzoni A, Pacifici A, Zanza A, et al. Assessment of real-time operative torque during nickel-titanium instrumentation with different lubricants. Appl Sci 2020;10(18):6201. DOI: 10.3390/app10186201.

() Jaypee Brothers Medical Publishers. 2021 Open Access This article is distributed under the terms of the Creative Commons Attribution 4.0 International License (https://creativecommons.org/licenses/by-nc/4.0/), which permits unrestricted use, distribution, and non-commercial reproduction in any medium, provided you give appropriate credit to the original author(s) and the source, provide a link to the Creative Commons license, and indicate if changes were made. The Creative Commons Public Domain Dedication waiver (http://creativecommons.org/publicdomain/zero/1.0/) applies to the data made available in this article, unless otherwise stated. 
8. Chandler N, Chellappa D. Lubrication during root canal treatment. Aust Endod J 2019 ;45(1):106-110. DOI: 10.1111/aej.12282.

9. Seracchiani M, Miccoli G, Di Nardo D, et al. Effect of flexural stress on torsional resistance of NiTi instruments. J Endod 2020. DOI: 10.1016/ j.joen.2020.10.011S0099-2399(20)30773-1.

10. Gambarini G, Seracchiani M, Zanza A, et al. Influence of shaft length on torsional behavior of endodontic nickel-titanium instruments. Odontology 2020. DOI: 10.1007/s10266-020-00572-2in press.

11. Gambarini G, Miccoli G, Nardo DD, et al. Torsional resistance of two new heat treated nickel titanium rotary instruments: an in vitro evaluation. Pesqui Bras Odontopediatria Clin Integr 2020;20:1-7. DOI: 10.1590/pboci.2020.156.
12. D'Angelo M, Del Giudice A, Mazzoni A, et al. Fatigue resistance of two Nickel-Titanium rotary instruments before and after ex vivo root canal treatment. J Contemp Dental Pract 2020;21(7):728-732. DOI: 10.5005/jp-journals-10024-2875.

13. Gambarini G, Cicconetti A, Di Nardo D, et al. Influence of different heat treatments on torsional and cyclic fatigue resistance of nickeltitanium rotary files: a comparative study. Appl Sci (Switzerland) 2020;10(16):5604. DOI: 10.3390/app10165604.

14. Di Nardo D, Miccoli G, Mazzoni A, et al. Centering ability of a new nickel-titanium rotary instruments with a peculiar flat-side design: an in vitro study. J Contemp Dent Pract 2020;21(5):539-542. DOI: 10.5005/jp-journals-10024-2829. 